\title{
Association between baseline LDL-C and prognosis among patients with coronary artery disease and advanced kidney disease
}

Bo Wang ${ }^{1+}$, Shiqun Chen ${ }^{1 \dagger}$, Jin Liu' ${ }^{1 \dagger}$, Yan Liang ${ }^{2}$, Liangguang Meng ${ }^{1}$, Xiaoming Yan ${ }^{3}$, Haozhang Huang ${ }^{4}$, Guanzhong Chen ${ }^{5}$, Zhidong Huang ${ }^{1}$, Danyuan Xu' ${ }^{1}$ Min Li ${ }^{1}$, Jingjing Liang ${ }^{4}$, Shuangxin Liư ${ }^{6}$, Jiyan Chen ${ }^{1,4,5}$, Yong Liu ${ }^{1,4,5^{*}}$ and Ning Tan ${ }^{1,4,5^{*}}$

\begin{abstract}
Background: Lower low-density lipoprotein cholesterol $(L D L-C)$ is significantly associated with improved prognosis in patients with coronary artery disease (CAD). However, LDL-C reduction does not decrease all-cause mortality among CAD patients when renal function impairs. The association between low baseline $L D L-C(<1.8 \mathrm{mmol} / \mathrm{L})$ and mortality is unknown among patients with CAD and advanced kidney disease (AKD). The current study aimed to evaluate prognostic value of low baseline LDL-C level for all-cause death in these patients.

Methods: In this observational study, 803 CAD patients complicated with AKD (eGFR $<30 \mathrm{~mL} / \mathrm{min} / 1.73 \mathrm{~m}^{2}$ ) were enrolled between January 2008 to December 2018. Patients were divided into two groups (LDL-C $<1.8 \mathrm{mmol} / \mathrm{L}, n=$ 138; LDL-C $\geq 1.8 \mathrm{mmol} / \mathrm{L}, n=665$ ). We used Kaplan-Meier methods and Cox regression analyses to assess the association between baseline low LDL-C levels and long-term all-cause mortality.

Results: Among 803 participants (mean age 67.4 years; 68.5\% male), there were 315 incidents of all-cause death during a median follow-up of 2.7 years. Kaplan-Meier analysis showed that low LDL-C levels were associated with worse prognosis. After adjusting for full 24 confounders (e.g., age, diabetes, heart failure, and dialysis, etc.), multivariate Cox regression analysis revealed that lower $\mathrm{LDL}-\mathrm{C}$ level $(<1.8 \mathrm{mmol} / \mathrm{L})$ was significantly associated with higher risk of all-cause death (adjusted HR, 1.38; 95\% Cl, 1.01-1.89).
\end{abstract}

Conclusions: Our data demonstrated that among patients with CAD and AKD, a lower baseline LDL-C level $(<1.8$ $\mathrm{mmol} / \mathrm{L}$ ) did not present a higher survival rate but was related to a worse prognosis, suggesting a cautiousness of too low LDL-C levels among patients with CAD and AKD.

Keywords: Baseline low-density lipoprotein cholesterol $\bullet$ coronary artery disease $\cdot$ advanced kidney disease $\cdot$ all-cause mortality

\footnotetext{
* Correspondence: liuyong@gdph.org.cn; tanning100@126.com

${ }^{\dagger}$ Bo Wang, Shiqun Chen and Jin Liu contributed equally to this work.

${ }^{1}$ Department of Cardiology, Guangdong Provincial Key Laboratory of Coronary Heart Disease Prevention, Guangdong Cardiovascular Institute, Guangdong Provincial People's Hospital, Guangdong Academy of Medical Sciences, Guangzhou 510080, China

Full list of author information is available at the end of the article
}

(c) The Author(s). 2021 Open Access This article is licensed under a Creative Commons Attribution 4.0 International License, which permits use, sharing, adaptation, distribution and reproduction in any medium or format, as long as you give appropriate credit to the original author(s) and the source, provide a link to the Creative Commons licence, and indicate if changes were made. The images or other third party material in this article are included in the article's Creative Commons licence, unless indicated otherwise in a credit line to the material. If material is not included in the article's Creative Commons licence and your intended use is not permitted by statutory regulation or exceeds the permitted use, you will need to obtain permission directly from the copyright holder. To view a copy of this licence, visit http://creativecommons.org/licenses/by/4.0/ The Creative Commons Public Domain Dedication waiver (http://creativecommons.org/publicdomain/zero/1.0/) applies to the data made available in this article, unless otherwise stated in a credit line to the data. 


\section{Introduction}

The efficacy of the low-density lipoprotein cholesterol (LDL-C) reduction can ameliorate the cardiovascular mortality of patients with coronary artery disease (CAD) [17]. For patients with $\mathrm{CAD}$ and advanced kidney disease (AKD, defined as an eGFR below $30 \mathrm{~mL} / \mathrm{min} / 1.73 \mathrm{~m} 2$ ), ISCHEMIA-CKD study recommended a criterion of optimal medical therapy that LDL-C should be controlled below $1.8 \mathrm{mmol} / \mathrm{L}$ [8]. A systematic review and metaanalysis conducted by the Cholesterol Treatment Trialists (CTT) and the SHARP trial suggested that in patients with poor renal function would not result in an improvement of clinical outcomes $[9,10]$. Kovesdy et al.'s study also found that lower LDL-C levels were associated with higher mortality in patients who have moderate and advanced CKD and are not yet on dialysis [11].

However, for patients with CAD and AKD (eGFR < 30 $\mathrm{mL} / \mathrm{min} / 1.73 \mathrm{~m} 2$ ), the association between low baseline LDL-C $(<1.8 \mathrm{mmol} / \mathrm{L})$ and mortality is unknown. Therefore, the present study aimed to investigate the lower baseline LDL-C value in terms of their prognostic value for all-cause death in patients with CAD and AKD.

\section{Method}

\section{Study design and participants}

This observational study was conducted at Guangdong Provincial People's Hospital in China. From January
2008 to December 2018 and was firstly registered with ClinicalTrials.gov on 29th May 2020 (NCT04407936). We retrospectively enrolled 1030 consecutive patients complicated with AKD $\left(e G F R<30 \mathrm{~mL} / \mathrm{min} / 1.73 \mathrm{~m}^{2}\right)$ and undergoing coronary angiography (CAG). We excluded 116 patients without CAD, 16 patients who did not test for LDL-C, and 95 patients who were lost to follow-up. Finally, 803 patients were included in this analysis (see Fig. 1). The study protocol was approved by the Guangdong Provincial People's Hospital ethics committee, and the study was performed according to the Declaration of Helsinki.

\section{Procedures}

At enrollment, we collected baseline data including demographic characteristics, coexisting conditions, laboratory examinations, and medications. CAG or percutaneous coronary intervention (PCI) was performed in accordance with standard clinical practice guidelines [12-14].

\section{Clinical outcome and definition}

AKD was defined as an estimated glomerular filtration rate $($ eGFR $)<30 \mathrm{~mL} /\left(\min \cdot 1.73 \mathrm{~m}^{2}\right)$, which was calculated by the Modification of Diet in Renal Disease (MDRD) formula [15]. CAD was confirmed by CAG. LDL-C value was measured by overnight fasting blood

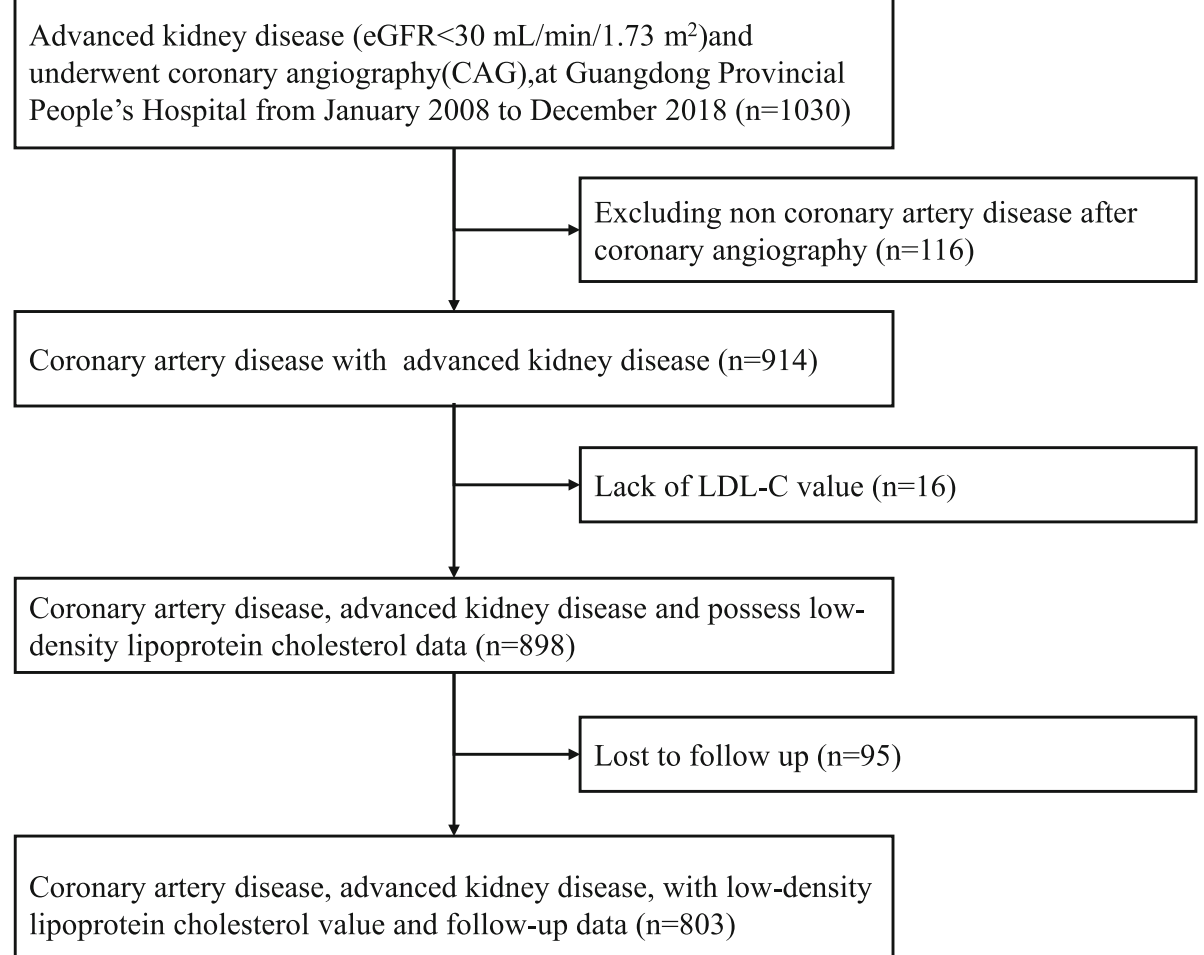

Fig. 1 Study flow chart 
sample and used the first test result during hospitalization. Congestive heart failure (CHF) was defined as New York Heart Association (NYHA) class $>2$ or Killip class $>1$. Hypertension was definitively present if the participant was under treatment with antihypertensive medication or had systolic blood pressure $\geq 140$ $\mathrm{mmHg}$ or diastolic blood pressure $\geq 90 \mathrm{mmHg}$ [16]. Follow-up data were monitored and recorded by trained nurses through outpatient interviews and telephones.

\section{Statistical analysis}

Descriptive statistics are reported as the mean \pm standard deviation $(\mathrm{SD})$, median (interquartile range $[\mathrm{IQR}]$ ), or number and percentage when appropriate. The chisquare test was used to compare differences between categorical variables. An independent-samples Student's t-test was used to compare continuous variables with normal distribution, and the Wilcoxon rank sum test was used to compare continuous variables. Analysis of the rate of death from any cause was performed with the use of Kaplan-Meier methods, with survival curves for the probability of remaining outcome-free in the two groups divided by LDL-C level of $1.8 \mathrm{mmol} / \mathrm{L}$. The two curves were compared with the method of the log-rank test. Cox proportional hazards models were used to investigate the associations of baseline LDL-C levels with long-term all-cause death. The following six multivariate Cox models were sequentially constructed with different covariates: (1) adjusted for age and male; (2) adjusted for nutritional status: albumin; (3) adjusted for lipid variables: total cholesterol, triglyceride, high-density lipoprotein cholesterol; (4) adjusted for variables associated with cardiovascular disease: acute coronary syndrome, congestive heart failure, hypertension, peripheral arterial disease, previous acute myocardial infarction, PCI, Lg ProBNP; (5) adjusted for variables associated with kidney disease: dialysis, $15 \leq \mathrm{eGFR}<30 \mathrm{ml} / \mathrm{min} / 1.73 \mathrm{~m}^{2}$ vs. eGFR $<15 \mathrm{ml} / \mathrm{min} / 1.73 \mathrm{~m}^{2}$; (6) adjusted for full multivariate variables: age, male, current smoker, acute coronary syndrome, congestive heart failure, hypertension, diabetes mellitus, dialysis, anemia, peripheral arterial disease, $15 \leq \mathrm{eGFR}<30 \mathrm{ml} / \mathrm{min} / 1.73 \mathrm{~m}^{2}$ vs. eGFR $<15 \mathrm{ml} /$ $\min / 1.73 \mathrm{~m}^{2}$, previous acute myocardial infarction, PCI, white blood cell count, albumin, total cholesterol, triglyceride, high-density lipoprotein cholesterol, Lg ProBNP, Lg D-dimer, ACEI/ARB, $\beta$-blockers, statins, diuretics. The hazard ratio (HR) and 95\% confidence interval (CI) were calculated. We performed multiple imputations using Markov chain Monte Carlo (MCMC) and fully conditional specification (FCS) to avoid exclusion of patients with missing values. 5 variables were conducted by nonparametric multiple imputation with missing-atrandom assumptions [17, 18]. Patients who had missing predictors over $20 \%$ were excluded. Variables were significant at $P<0.05$ according to univariate Cox regression, and those associated with mortality according to clinical experience were further controlled by multivariable Cox regression in 6 different models. Model 1 adjusted age and gender. Model 2 adjusted nutritional status (albumin). Mode 3 adjusted 3 lipid variables (total cholesterol, triglyceride, high density lipoprotein cholesterol). Model 4 adjusted for variables associated with cardiovascular disease. Model 5 adjusted for variables associated with kidney disease. And model 6 adjusted for full multivariate variables. We also performed sensitivity analysis, including comparing the differences before and after data filling and subgroup analysis. Potential nonlinear associations between the concentration of LDL-C and long-term all-cause mortality were examined with restricted cubic splines. All data analyses were performed using SAS, version 9.4 (SAS Institute, Cary, NC) and $\mathrm{R}$ software, version 4.0.1 (R Foundation for Statistical Computing). All $p$ values $<0.05$ were considered to represent statistical significance.

\section{Result}

From January 2008 to December 2018, a total of 803 patients were included in the study. The mean age was $67.4 \pm 10.3$ years, and $550(68.5 \%)$ were male. There was 312 (38.9\%) death during a median follow-up of 2.7 (IQR 1.6-4.4) years. A total of 803 eligible patients were divided into a low LDL-C group $(n=138)$ and a high LDL-C group $(n=665)$. All of the patients' baseline clinical characteristics are shown in Table 1.

Generally, participants with low LDL-C levels had lower HDL-C levels. In the low LDL-C group, patients were more likely to have diabetes mellitus $(62.3 \%$ vs $51.6 \%, p=0.03)$, hypertension $(89.9 \%$ vs $79.7 \%, p=$ $0.008)$, and anemia $(91.2 \%$ vs $80.9 \%, p=0.005)$ and to be undergoing dialysis $(62.3 \%$ vs $51.6 \%, p<0.001)$. The proportions of male, current smoker, CHF, peripheral arterial disease (PAD), previous acute myocardial infarction (AMI), PCI and medications were similar in both groups. Based on the comparison of complete data and missing data, data are missing at random (Supplementary Table 1).

Kaplan-Meier survival analysis demonstrated that patients in the low LDL-C group had a significantly higher long-term all-cause mortality than those in the high LDL-C group (log-rank $P=0.002$; Fig. 2 ).

Univariate regression analysis showed that lower baseline LDL-C level was significantly associated with the primary endpoint (Supplementary Table 2). Potential predictive factors for all-cause long-term mortality were adjusted using multivariable Cox regression analysis. Adjusted for full multivariate variables (including 24 confounders such as age, diabetes, heart failure, and dialysis, etc), baseline $\mathrm{LDL}-\mathrm{C}<1.8 \mathrm{mmol} / \mathrm{L}$ was associated with 
Table 1 Baseline characteristics

\begin{tabular}{|c|c|c|c|c|c|}
\hline Characteristic $^{\mathrm{a}}$ & Missing Data & $\begin{array}{l}\text { Overall } \\
(N=803)\end{array}$ & $\begin{array}{l}\mathrm{LDL}-\mathrm{C} \geq 1.8 \mathrm{mmol} / \mathrm{L} \\
(N=665)\end{array}$ & $\begin{array}{l}\text { LDL-C }<1.8 \mathrm{mmol} / \mathrm{L} \\
(N=138)\end{array}$ & $P$ value \\
\hline \multicolumn{6}{|l|}{ Demographic characteristics } \\
\hline Age, year & $0(0)$ & $67.4(10.3)$ & $67.5(10.2)$ & $66.8(10.8)$ & 0.44 \\
\hline Male, n (\%) & $0(0)$ & $550(68.5)$ & $450(67.7)$ & $100(72.5)$ & 0.32 \\
\hline \multicolumn{6}{|l|}{ Coexisting conditions } \\
\hline Current smoker, n (\%) & $0(0)$ & $117(14.6)$ & 99 (14.9) & $18(13.0)$ & 0.67 \\
\hline ACS, n (\%) & $0(0)$ & $386(48.1)$ & $328(49.3)$ & $58(42.0)$ & 0.14 \\
\hline $\mathrm{CHF}, \mathrm{n}(\%)$ & $0(0)$ & $381(47.4)$ & $312(46.9)$ & $69(50.0)$ & 0.57 \\
\hline Hypertension, n (\%) & $0(0)$ & $654(81.4)$ & $530(79.7)$ & $124(89.9)$ & 0.008 \\
\hline Diabetes mellitus, n (\%) & $0(0)$ & $429(53.4)$ & $343(51.6)$ & $86(62.3)$ & 0.03 \\
\hline Dialysis, n (\%) & $0(0)$ & $283(35.2)$ & $216(32.5)$ & $67(48.6)$ & $<0.001$ \\
\hline Anemia, n (\%) & $2(0.2)$ & $662(82.6)$ & $537(80.9)$ & $125(91.2)$ & 0.005 \\
\hline PAD, n (\%) & $0(0)$ & $91(11.3)$ & $80(12.0)$ & $11(8.0)$ & 0.22 \\
\hline eGFR, $\mathrm{ml} / \mathrm{min} / 1.73 \mathrm{~m}^{2}$ & $0(0)$ & $18.0(8.3)$ & $18.4(8.1)$ & $15.9(8.9)$ & 0.001 \\
\hline $15 \leq \mathrm{eGFR}<30 \mathrm{ml} / \mathrm{min} / 1.73 \mathrm{~m}^{2}, \mathrm{n}(\%)$ & $0(0)$ & $499(62.1)$ & $431(64.8)$ & $68(49.3)$ & 0.001 \\
\hline Previous AMI, n (\%) & $0(0)$ & $64(8.0)$ & $54(8.1)$ & $10(7.2)$ & 0.86 \\
\hline $\mathrm{PCl}, \mathrm{n}(\%)$ & $0(0)$ & $440(54.8)$ & $365(54.9)$ & $75(54.3)$ & 0.98 \\
\hline \multicolumn{6}{|l|}{ Laboratory examination } \\
\hline WBC, $10^{9} / \mathrm{L}$ & $2(0.2)$ & $8.6(3.3)$ & $8.6(3.3)$ & $8.5(3.7)$ & 0.67 \\
\hline$A L B, g / L$ & $1(0.1)$ & $32.7(5.1)$ & $32.9(5.2)$ & $32.0(4.5)$ & 0.06 \\
\hline Total Cholesterol, mmol/L & $1(0.1)$ & $4.4(1.3)$ & $4.6(1.3)$ & $3.2(0.8)$ & $<0.001$ \\
\hline LDLC, mmol/L & $0(0)$ & $2.7(1.0)$ & $2.9(0.9)$ & $1.5(0.3)$ & $<0.001$ \\
\hline TRIG, mmol/L & $0(0)$ & $1.3(1.36)$ & $2.0(1.3)$ & $1.8(1.4)$ & 0.09 \\
\hline $\mathrm{HDLC}, \mathrm{mmol} / \mathrm{L}$ & $0(0)$ & $0.9(0.3)$ & $0.9(0.3)$ & $0.8(0.2)$ & $<0.001$ \\
\hline Lg ProBNP, pg/mL & $113(14.1)$ & $3.7(0.7)$ & $3.7(0.7)$ & $3.8(0.7)$ & 0.18 \\
\hline Lg D-dimer, ng/mL & $42(5.2)$ & $3.1(0.4)$ & $3.1(0.4)$ & $3.0(0.4)$ & 0.71 \\
\hline \multicolumn{6}{|l|}{ Medications } \\
\hline ACEI/ARB, n (\%) & $0(0)$ & $329(41.0)$ & $268(40.3)$ & $61(44.2)$ & 0.45 \\
\hline$\beta$-blockers, n (\%) & $0(0)$ & $542(67.5)$ & $453(68.1)$ & $89(64.5)$ & 0.47 \\
\hline Statins, n (\%) & $0(0)$ & 717 (89.3) & $593(89.2)$ & $124(89.9)$ & 0.93 \\
\hline Diuretics, n (\%) & $0(0)$ & $337(42.0)$ & $281(42.3)$ & $56(40.6)$ & 0.79 \\
\hline \multicolumn{6}{|l|}{ Events } \\
\hline Death, n (\%) & $0(0)$ & $312(38.9)$ & $238(35.8)$ & $74(53.6)$ & $<0.001$ \\
\hline
\end{tabular}

${ }^{a}$ Data are presented as the mean value standard deviation or percentage of participants

Abbreviations: $L D L-C$ Low-density lipoprotein cholesterol; $A C S$ Acute coronary syndrome; CHF Congestive heart failure; PAD Peripheral arterial disease; $e G F R$

Estimated glomerular filtration rate; $A M I$ Acute myocardial infarction; $P C I$ Percutaneous coronary intervention; $H D L-C$ High-density lipoprotein cholesterol; TRIG

Triglycerides; WBC White blood cell; pro-BNP Pro-brain natriuretic peptide; ACEI Angiotensin-Converting Enzyme Inhibitors; ARB Angiotensin Receptor Blockers

all-cause long-term mortality (HR: 1.38, 95\% CI: 1.01$1.89, p=0.04)$. and other five models have similar results (see Table 2).

Subgroup analyses were conducted by dialysis or not, ACS, and diabetes mellitus (DM) (see Table 3). In the subgroup analysis of long-term all-cause mortality among patients undergoing dialysis and with DM, the relation was similar (HR: 1.66, 95\% CI: $1.03-2.68, \mathrm{p}=0.04 ; \mathrm{HR}: 1.59,95 \%$ CI: $1.05-2.40, p=$ $0.03)$.

\section{Discussion}

To our knowledge, this is the first study to evaluate the association between baseline LDL-C levels and longterm all-cause mortality in patients with CAD and AKD. Over a median follow-up period of 2.7 years, the overall incidence of all-cause death was $38.9 \%$ among patients with CAD and AKD at very high-risk in our study. Our results showed that the risk with respect to all-cause mortality was more pronounced among patients with baseline LDL-C level $<1.8 \mathrm{mmol} / \mathrm{L}$. After adjusting for 


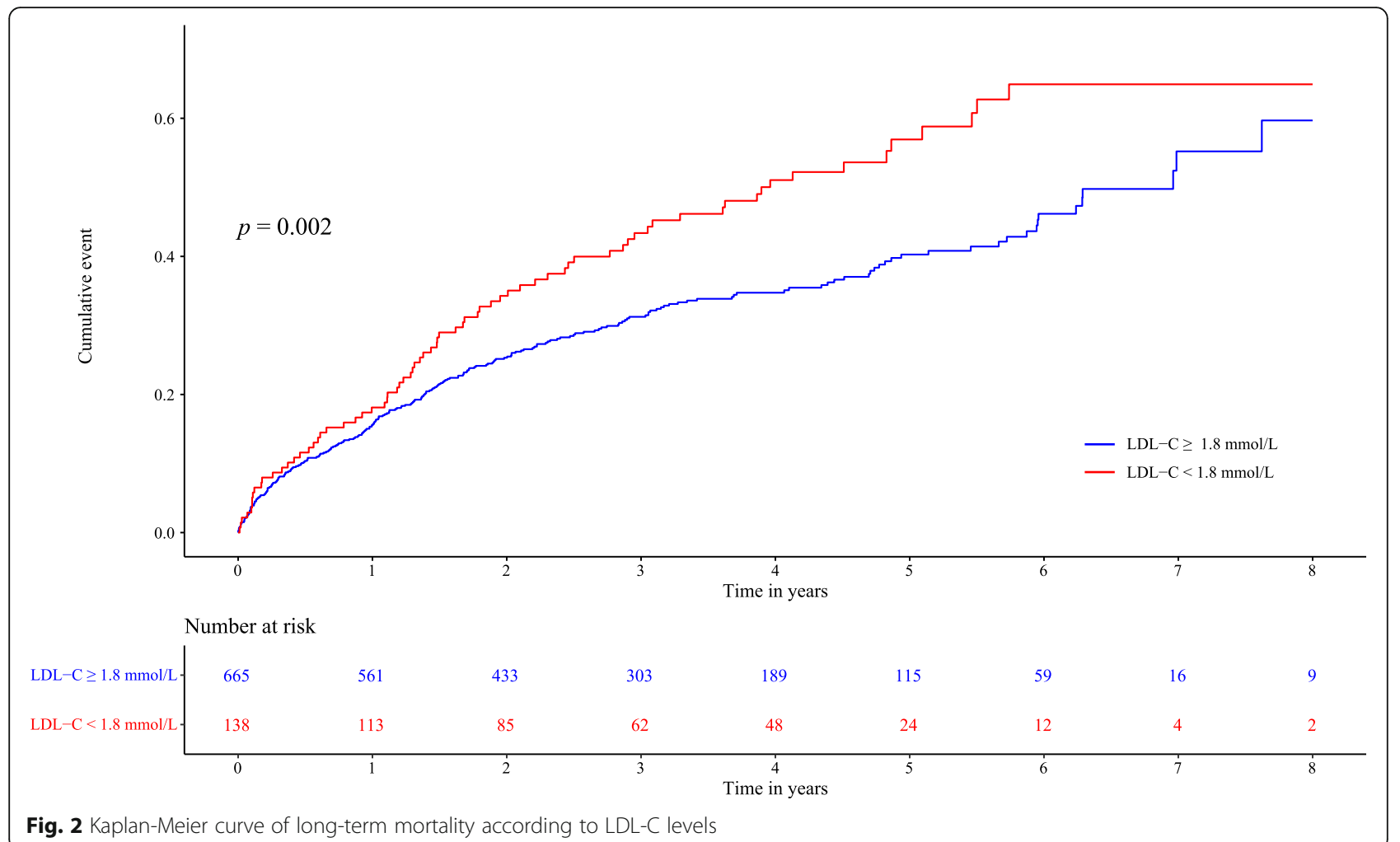

confounding factors, our data suggested that lower baseline LDL-C level $(<1.8 \mathrm{mmol} / \mathrm{L})$ was significantly associated with higher long-term all-cause mortality among patients with CAD and AKD. Similar results were also observed in different subgroups.

Table 2 Cox proportional hazard ratios of $L D L-C<1.8 \mathrm{mmol} / \mathrm{L}$ vs. $L D L-C \geq 1.8 \mathrm{mmol} / \mathrm{L}$ for long-term all-cause mortality in different models

\begin{tabular}{lllll}
\hline & HR & $\mathbf{9 5 \%} \mathbf{C l}$ & & $\boldsymbol{P}$ Value \\
\hline Univariate Cox model & 1.53 & 1.18 & 1.99 & 0.001 \\
Model 1 & 1.52 & 1.17 & 1.98 & 0.002 \\
Model 2 & 1.47 & 1.13 & 1.91 & 0.004 \\
Model 3 & 1.58 & 1.16 & 2.14 & 0.003 \\
Model 4 & 1.40 & 1.08 & 1.83 & 0.012 \\
Model 5 & 1.45 & 1.12 & 1.88 & 0.005 \\
Model 6 & 1.38 & 1.01 & 1.89 & 0.042 \\
\hline
\end{tabular}

Model 1: Adjusted for age and male

Model 2: Adjusted for nutritional status: albumin

Model 3: Adjusted for lipid variables: total cholesterol, triglyceride, highdensity lipoprotein cholesterol

Model 4: Adjusted for variables associated with cardiovascular disease: ACS, $\mathrm{CHF}$, hypertension, PAD, previous AMI, PCl, Lg ProBNP

Model 5: Adjusted for variables associated with kidney disease: dialysis, $15 \leq$ eGFR $<30 \mathrm{ml} / \mathrm{min} / 1.73 \mathrm{~m}^{2}$ vs. eGFR $<15 \mathrm{ml} / \mathrm{min} / 1.73 \mathrm{~m}^{2}$

Model 6: Adjusted for full multivariate variables: age, male, current smoker, ACS, CHF, hypertension, diabetes mellitus, dialysis, anemia, PAD, $15 \leq \mathrm{eGFR}<$ $30 \mathrm{ml} / \mathrm{min} / 1.73 \mathrm{~m}^{2}$ vs. eGFR $<15 \mathrm{ml} / \mathrm{min} / 1.73 \mathrm{~m}^{2}$, previous AMI, PCI, WBC, albumin, total Cholesterol, triglyceride, high-density lipoprotein cholesterol, $\mathrm{Lg}$ ProBNP, Lg D-dimer, ACEI/ARB, $\beta$-blockers, statins, diuretics
Most previous studies referred to LDL-C focused on the relationship between LDL-C concentration after lipid-lowering therapy and clinical outcomes. Although, reduced LDL-C levels after lipid lowering therapy can improve the prognosis of CAD patients, but the effect would be weakened when renal function deteriorates. And, most trials involving patients with cardiovascular disease have either excluded patients with advanced kidney disease or included too few to permit a confident estimation of treatment benefits [19, 20]. Studies involving baseline LDL-C levels are limited.

Our study showed a negative relation between baseline LDL-C levels and long-term outcomes in patients with CAD and AKD. Similarly, a recent meta-analysis showed that benefits of lowering LDL-C were absent when the baseline LDL-C level was less than $<2.6 \mathrm{mmol} / \mathrm{L}$ [21]. Findings of an observational study conducted by Kovesdy et al. also showed that lower LDL cholesterol concentration was relevant to higher risk of mortality [11]. Furthermore, there were some previous studies investigating the inverse relations between baseline or admission LDL-C levels and clinical outcomes in the subgroups of coronary artery disease. Wang et al. demonstrated that lower admission LDL-C levels $(<2.6$ $\mathrm{mmol} / \mathrm{L}$ ) were associated with better in-hospital survival in patients with acute coronary syndrome [22]. Cho et al. found that among patients with acute myocardial infarction, lower baseline LDL-C levels $(<1.8 \mathrm{mmol} / \mathrm{L})$ 
Table 3 Subgroup analysis of LDL-C level with mortality among CAD and CKD patients

\begin{tabular}{|c|c|c|c|c|c|c|c|}
\hline \multirow[t]{2}{*}{ Subgroup } & \multicolumn{2}{|c|}{ No of events / No of patients } & \multicolumn{4}{|c|}{ Multivariate Cox Regression } & \multirow{2}{*}{$\begin{array}{l}\mathrm{P} \text { for } \\
\text { interaction }\end{array}$} \\
\hline & LDL-C $<1.8$ & LDL-C $\geq 1.8$ & $\mathrm{HR}$ & $95 \% \mathrm{Cl}$ & & $P$ value & \\
\hline \multicolumn{8}{|l|}{ On dialysis } \\
\hline Yes & $39 / 67(58.2 \%)$ & $86 / 216(39.8 \%)$ & 1.66 & 1.03 & 2.68 & 0.04 & 0.38 \\
\hline No & $36 / 71(50.7 \%)$ & $154 / 449(34.3 \%)$ & 1.22 & 0.79 & 1.88 & 0.38 & \\
\hline \multicolumn{8}{|l|}{ ACS } \\
\hline Yes & $31 / 58(53.4 \%)$ & 120/328 (36.6\%) & 1.36 & 0.84 & 2.19 & 0.21 & 0.76 \\
\hline No & $44 / 80(55.0 \%)$ & 120/337 (35.6\%) & 1.33 & 0.87 & 2.02 & 0.18 & \\
\hline \multicolumn{8}{|l|}{ DM } \\
\hline Yes & $48 / 86(55.8 \%)$ & $129 / 343(37.6 \%)$ & 1.59 & 1.05 & 2.40 & 0.03 & 0.35 \\
\hline No & $27 / 52(51.9 \%)$ & $111 / 322(34.5 \%)$ & 1.30 & 0.78 & 2.18 & 0.32 & \\
\hline
\end{tabular}

Abbreviations: ACS Acute coronary syndrome; DM Diabetes mellitus

Adjusted for full multivariate variables: age, male, current smoker, ACS, CHF, hypertension, DM, dialysis, anemia, PAD, $15 \leq$ eGFR $<30 \mathrm{ml} / \mathrm{min} / 1.73 \mathrm{~m}{ }^{2}$ vs. eGFR $<15$ $\mathrm{ml} / \mathrm{min} / 1.73 \mathrm{~m}^{2}$, previous AMI, PCl, WBC, albumin, total Cholesterol, triglyceride, high-density lipoprotein cholesterol, Lg ProBNP, Lg D-dimer, ACEI/ARB, $\beta$-blockers, statins, diuretics

were associated with higher mortality at 12 months [23]. Reddy et al. also found that in the AMI patients lower baseline LDL-C levels $(<2.0 \mathrm{mmol} / \mathrm{L})$ were associated with higher in-hospital mortality [24]. According to AlMallah et al's study, the relation of lower LDL-C levels $(<2.7 \mathrm{mmol} / \mathrm{L})$ and poorer prognosis still existed [25]. There are noteworthy similarities between our study and the above four studies. Our study and the four studies all focused on CAD patients. The results of these studies, as well as ours, indicated the paradoxical phenomenon that low LDL-C levels are correlated to poor prognosis. The Findings from a study conducted by $\mathrm{Hu}$ et al. enrolling 3441 patients with CKD showed that no significant benefit was seen from statins in kidney function deterioration for patients with CKD [26]. While, for patients with baseline eGFR $<45 \mathrm{~mL} / \mathrm{min} /$ $1.73 \mathrm{~m} 2$ (CKD stage 3B-5), the effect of statins was significant. Among patients included in our study, renal function was all below $30 \mathrm{~mL} / \mathrm{min} / 1.73 \mathrm{~m} 2$. According to the conclusion of $\mathrm{Hu}$ et al.'s study, patients enrolled in our study would benefit from the use of statins. Furthermore, use of statins is important part of secondary prevention of coronary artery disease, and has been demonstrated to improve outcomes in patients with coronary heart disease. In our study, the use of statins can reduce the risk of long-term all-cause mortality by $43 \%$ (unadjusted HR: 0.63, 95\% CI: 0.46-0.87). Thus, we included statins in the multivariate Cox model 6 , in order to adjust for confounding effects of statins on prognosis.

There are several caveats to consider with regard to the interpretation of our results. First, in a previous study, an inverse association between LDL-C levels and incident cancer incidences was observed [27]. Although cardiovascular disease (CVD) is the leading cause of mortality among patients with CKD [28], some patients may die because of incident cancer during the follow-up period. Unfortunately, our follow-up data lack records of specific causes of death. Moreover, evidence is emerging that cholesterol is related to the regulation of immune cell function by improving their antitumor activity and activating immune signaling, which may provide novel insights into the role of cholesterol in the development of cancer [29-31]. Second, a plausible explanation for the absence of a positive correlation between LDL-C and long-term all-cause mortality is that patients with CAD and AKD in the low LDL-C group were in poor condition and had many complications. Patients with low LDL-C concentrations $(<1.8 \mathrm{mmol} / \mathrm{L})$ had higher prevalence of cardiovascular disease related comorbidities and other diseases or conditions associated with prognosis, including diabetes mellitus (62.3\% vs. 51.7\%), hypertension $(89.9 \%$ vs. $79.7 \%)$, anemia $(91.3 \%$ vs. $81.0 \%)$ and poor renal function. Similarly, in Kovesdy et al.'s study, the paradoxical relationship between lower LDL-C levels and higher risk of death attenuated as the adjustment variables increased. After further consideration of baseline confounders, particularly malnutritioninflammation-cachexia syndrome, lower LDL-C concentration was no longer independently relevant to increased risk of mortality [11]. Furthermore, according to the result of our subgroup analysis, patients who were on dialysis and suffering from diabetes mellitus also had a higher risk of death when $\mathrm{LDL}-\mathrm{C}<1.8 \mathrm{mmol} / \mathrm{L}$. The increased long-term mortality may result from basic diseases to some extent.

According to our results of the association between low baseline LDL-C levels and increased long-term allcause mortality in patients with CAD and AKD, our data may provide clinical evidence for the management of LDL-C in this population. First, in this very high-risk population, low baseline LCL-C level may be a reflection of patients with multiple diseases and adverse 
conditions. In the long-term management of patients with CAD and AKD, excessively low LDL-C may provide a new risk assessment indicator for clinical decisions. Second, patients with LDL-C at very low levels should be carefully assessed and if necessary, screened for other diseases that may affect mortality. On the other hand, during the treatment of high LDL-C, regular follow-up is required to dynamically evaluate the lipid levels and adjust the lipid-lowering strategies. Ultimately, new multicenter prospective or RCT clinical studies for baseline LDL-C management in these patients should be conducted to evaluate the appropriate lipid management strategy.

\section{Limitation}

This study has several limitations. First, this study was a retrospective single-center study conducted at Guangdong Cardiovascular Institute, Guangdong Provincial People's Hospital in China. However, the sample size of the study was relatively large; thus, this study can be the basis for further prospective RCTs. Second, in this study, we used only baseline data of LDL-C, and we lacked LDL-C data during the follow-up period. The long-term prognosis correlation may be affected by treatment such as statins, kidney function and other factors. However, we corrected for mixed factors such as dialysis dependence, statin treatment when discharged, age, and other risk factors. Third, there was limited data for the included patients, without information about BMI which might help us assess nutritional status. However, we chose the serum albumin concentration as the measure of nutritional status. Ultimately, the outcome of the study was defined as all-cause death, and some specific reasons may not be clear. However, cardiovascular death was the leading cause of death in these patients.

\section{Conclusion}

This study is the first to find that among very high-risk patients with CAD and AKD, a lower baseline LDL-C level $(<1.8 \mathrm{mmol} / \mathrm{L})$ did not predict a higher survival rate but was associated with a worse prognosis. Our findings suggested that LDL-C may not be "the lower, the better" among all patients with CAD, and may even harm those with CAD combined with AKD. These findings suggest an awareness of striking a balance to avoid LDL cholesterol levels that are too low for mortality and need verification in further randomized clinical trials among patients with CAD and AKD.

\footnotetext{
Abbreviations

LDL-C: Low-density lipoprotein cholesterol; CAD: Coronary artery disease; AKD: Advanced kidney disease; CAG: Coronary angiography;

PCl: Percutaneous coronary intervention; CHF: Congestive heart failure; HR: Hazard ratio; Cl: Confidence interval; PAD: Peripheral arterial disease; AMI: Previous acute myocardial infarction; DM: Diabetes mellitus
}

\section{Supplementary Information}

The online version contains supplementary material available at https://doi. org/10.1186/s12882-021-02375-1.

Additional file 1: Supplementary Table S1. Descriptive statistics among completed and missing data set. Supplementary Table S2. Univariable Cox regression analysis of long-term all-cause mortality.

\section{Acknowledgments \\ Special thanks to Professor Ying Xian for helping with the study design (Duke Clinical Research Institute, Durham, NC, 27705, USA) and Dr. Chongyang Duan with the guidance on statistics (Southern Medical University, Guangzhou, 510515, China).}

\section{Authors' contributions}

SQC was the senior statistician. JYC and NT were the scientific lead of GDICA and provided guidance for trial management. $Y L, S X L$ and $J L$ contributed to the design of the study. XMY and YL conducted data management. LGM and DYX performed the statistical analyses. BW, HZH, GZC, ZDH, ML and JJL wrote the first draft of the manuscript. All authors contributed to interpretation of the data, revision of the report, and approval of the final manuscript.

\section{Funding}

This study was supported by the National Natural Science Foundation of China (Grant No. 81670339 and Grant No. 81970311), Cardiovascular Research Foundation Project of the Chinese Medical Doctor Association (SCRFCMDA201216) and Beijing Lisheng Cardiovascular Health Foundation (LHJJ20141751).

\section{Availability of data and materials}

Not applicable at this stage. The datasets analyzed during the current study will be available from the corresponding author on reasonable request when the study is finished.

\section{Declarations}

Ethics approval and consent to participate

This study was conducted in accordance with the Declaration of Helsinki and was approved by the Research Ethics Committee of Guangdong Provincial People's Hospital, Guangdong Academy of Medical Sciences (No. GDREC2019555H[R1]). All traceable personal identifiers were removed from the analytic dataset to protect patients' privacy. For this reason, the requirement for informed consent was waived, which was approved by the Research Ethics Committee of Guangdong Provincial People's Hospital, Guangdong Academy of Medical Sciences (No. GDREC2019555H[R1]).

\section{Consent for publication}

Not applicable.

\section{Competing interests}

The authors declare that they have no competing interests.

\section{Author details}

'Department of Cardiology, Guangdong Provincial Key Laboratory of Coronary Heart Disease Prevention, Guangdong Cardiovascular Institute, Guangdong Provincial People's Hospital, Guangdong Academy of Medical Sciences, Guangzhou 510080, China. ªaoming People's Hospital, Maoming 525000, China. ${ }^{3}$ Department of Information Technology, Guangdong Provincial People's Hospital, Guangdong Academy of Medical Sciences, Guangzhou 510080, China. ${ }^{4}$ The Second School of Clinical Medicine, Southern Medical University, Guangzhou 510515, China. ${ }^{5}$ Guangdong Provincial People's Hospital, School of Medicine, South China University of Technology, Guangzhou 510100, China. 'Division of Nephrology, Guangdong Provincial People's Hospital, Guangdong Academy of Medical Sciences, Guangzhou 510080, China. 
Received: 5 February 2021 Accepted: 21 April 2021

Published online: 06 May 2021

\section{References}

1. Schwartz GG, Steg PG, Szarek M, Bhatt DL, Bittner VA, Diaz R, et al. Alirocumab and cardiovascular outcomes after acute coronary syndrome. N Engl J Med. 2018;379(22):2097-107. https://doi.org/10.1056/NEJMoa1801174.

2. Baigent $C$, Blackwell $L$, Emberson J, et al. Efficacy and safety of more intensive lowering of LDL cholesterol: a meta-analysis of data from 170,000 participants in 26 randomised trials. Lancet. 2010;376(9753):1670-81. https:// doi.org/10.1016/S0140-6736(10)61350-5.

3. Brugts JJ, Yetgin T, Hoeks SE, Gotto AM, Shepherd J, Westendorp RGJ, et al. The benefits of statins in people without established cardiovascular disease but with cardiovascular risk factors: meta-analysis of randomised controlled trials. Bmj. 2009:338(jun30 1):b2376. https://doi.org/10.1136/bmj.b2376.

4. Pedersen TR, Faergeman O, Kastelein JJ, Olsson AG, Tikkanen MJ, Holme I, et al. High-dose atorvastatin vs usual-dose simvastatin for secondary prevention after myocardial infarction: the IDEAL study: a randomized controlled trial. Jama. 2005;294(19):2437-45. https://doi.org/10.1001/jama.294.19.2437.

5. LaRosa JC, Grundy SM, Waters DD, et al. Intensive lipid lowering with atorvastatin in patients with stable coronary disease. N Engl J Med. 2005; 352(14):1425-35. https://doi.org/10.1056/NEJMoa050461.

6. Sabatine MS, Giugliano RP, Keech AC, Honarpour N, Wiviott SD, Murphy SA, et al. Evolocumab and clinical outcomes in patients with cardiovascular disease. N Engl J Med. 2017;376(18):1713-22. https://doi.org/10.1056/ NEJMoa1615664.

7. Cannon CP, Blazing MA, Giugliano RP, McCagg A, White JA, Theroux P, et al. Ezetimibe added to statin therapy after acute coronary syndromes. N Engl J Med. 2015;372(25):2387-97. https://doi.org/10.1056/NEJMoa1410489.

8. Bangalore S, Maron DJ, O'Brien SM, Fleg JL, Kretov El, Briguori C, et al. Management of Coronary Disease in patients with advanced kidney disease. N Engl J Med. 2020;382(17):1608-18. https://doi.org/10.1056/ NEJMoa1915925.

9. Herrington WG, Emberson J, Mihaylova $B$, et al. Impact of renal function on the effects of LDL cholesterol lowering with statin-based regimens: a meta-analysis of individual participant data from 28 randomised trials. Lancet Diabetes Endocrinol. 2016:4(10):829-39. https://doi.org/10.1016/S2213-8587(16)30156-5.

10. Baigent C, Landray MJ, Reith C, Emberson J, Wheeler DC, Tomson C, et al. The effects of lowering LDL cholesterol with simvastatin plus ezetimibe in patients with chronic kidney disease (study of heart and renal protection): a randomised placebo-controlled trial. Lancet. 2011;377(9784):2181-92. https://doi.org/10.1016/50140-6736(11)60739-3.

11. Kovesdy CP, Anderson JE, Kalantar-Zadeh K. Inverse association between lipid levels and mortality in men with chronic kidney disease who are not yet on dialysis: effects of case mix and the malnutrition-inflammationcachexia syndrome. J Am Soc Nephrol. 2007;18(1):304-11. https://doi.org/1 $0.1681 /$ ASN.2006060674.

12. Kushner FG, Hand M, Smith SC Jr, et al. 2009 focused updates: ACC/AHA guidelines for the management of patients with ST-elevation myocardial infarction (updating the 2004 guideline and 2007 focused update) and ACC/AHA/SCAI guidelines on percutaneous coronary intervention (updating the 2005 guideline and 2007 focused update) a report of the American College of Cardiology Foundation/American Heart Association task force on practice guidelines. J Am Coll Cardiol. 2009;54(23):2205-41. https://doi.org/1 0.1016/j.jacc.2009.10.015.

13. Ineid H, Anderson JL, Wright RS, et al. 2012 ACCF/AHA focused update of the guideline for the management of patients with unstable angina/nonST-elevation myocardial infarction (updating the 2007 guideline and replacing the 2011 focused update): a report of the American College of Cardiology Foundation/American Heart Association task force on practice guidelines. J Am Coll Cardiol. 2012;60:645-81.

14. Levine GN, Bates ER, Blankenship JC, et al. 2015 ACC/AHA/SCAl focused update on primary percutaneous coronary intervention for patients with STelevation myocardial infarction: an update of the 2011 ACCF/AHA/SCAI guideline for percutaneous coronary intervention and the 2013 ACCF/AHA guideline for the management of ST-elevation myocardial infarction. J Am Coll Cardiol. 2016;67:1235-50.

15. Aguiar-Souto P, Ferrante G, Del Furia F, Barlis P, Khurana R, Di Mario C. Frequency and predictors of contrast-induced nephropathy after angioplasty for chronic total occlusions. Int J Cardiol. 2010;139(1):68-74. https://doi.org/10.1016/j.jijcard.2008.10.006.
16. Wilson PW, D'Agostino RB, Levy D, Belanger AM, Silbershatz H, Kannel WB. Prediction of coronary heart disease using risk factor categories. Circulation. 1998;97(18):1837-47. https://doi.org/10.1161/01.CIR.97.18.1837.

17. van Buuren S, Boshuizen HC, Knook DL. Multiple imputation of missing blood pressure covariates in survival analysis. Stat Med. 1999;18(6):681-94. https://doi. org/10.1002/(SICl)1097-0258(19990330)18:6<681::AID-SIM71>3.0.CO;2-R.

18. Liu Y, De A, Navarese EP, et al. Multiple imputation by fully conditional specification for dealing with missing data in a large epidemiologic study association between baseline LDL-C level and Total and cardiovascular mortality after LDL-C lowering: a systematic review and meta-analysis. Int J Stat Med Res. 2015;4(3):287-95. https://doi.org/10.6000/1929-6029.2015.04.03.7.

19. Zannad F, Rossignol P. Cardiovascular outcome trials in patients with advanced kidney disease: time for action. Circulation. 2017;135(19):1769-71. https://doi.org/10.1161/CIRCULATIONAHA.117.027338.

20. Charytan D, Kuntz RE. The exclusion of patients with chronic kidney disease from clinical trials in coronary artery disease. Kidney Int. 2006;70(11):202130. https://doi.org/10.1038/sj.ki.5001934.

21. Navarese EP, Robinson JG, Kowalewski M, Kolodziejczak M, Andreotti F, Bliden $\mathrm{K}$, et al. Association between baseline LDL-C level and Total and cardiovascular mortality after LDL-C lowering: a systematic review and meta-analysis. Jama. 2018;319(15):1566-79. https://doi.org/10.1001/jama.2018.2525.

22. Wang TY, Newby LK, Chen AY, Mulgund J, Roe MT, Sonel AF, et al. Hypercholesterolemia paradox in relation to mortality in acute coronary syndrome. Clin Cardiol. 2009;32(9):E22-8. https://doi.org/10.1002/clc.20518.

23. Cho KH, Jeong MH, Ahn Y, Kim YJ, Chae SC, Hong TJ, et al. Low-density lipoprotein cholesterol level in patients with acute myocardial infarction having percutaneous coronary intervention (the cholesterol paradox). Am J Cardiol. 2010;106(8):1061-8. https://doi.org/10.1016/j.amjcard.2010.06.009.

24. Reddy VS, Bui QT, Jacobs JR, Begelman SM, Miller DP, French WJ. Relationship between serum low-density lipoprotein cholesterol and in-hospital mortality following acute myocardial infarction (the lipid paradox). Am J Cardiol. 2015; 115(5):557-62. https://doi.org/10.1016/j.amjcard.2014.12.006.

25. Al-Mallah MH, Hatahet H, Cavalcante JL, Khanal S. Low admission LDLcholesterol is associated with increased 3-year all-cause mortality in patients with non ST segment elevation myocardial infarction. Cardiol J. 2009;16(3): 227-33

26. Hu PJ, Wu MY, Lin TC, et al. Effect of statins on renal function in chronic kidney disease patients. Sci Rep. 2018;8(1):16276. https://doi.org/10.1038/s41 598-018-34632-z.

27. Li M, Lu J, Fu J, Wan Q, Wang T, Huo Y, et al. The association and joint effect of serum cholesterol, glycemic status with the risk of incident cancer among middle-aged and elderly population in China cardiometabolic disease and cancer cohort (4C)-study. Chronic kidney disease and coronary artery disease: JACC state-of-the-art review. Am J Cancer Res. 2020;10(3):975-86.

28. Sarnak MJ, Amann K, Bangalore S, Cavalcante JL, Charytan DM, Craig JC, et al. Chronic kidney disease and coronary artery disease: JACC state-of-theart review. J Am Coll Cardiol. 2019;74(14):1823-38. https://doi.org/10.1016/j. jacc.2019.08.1017.

29. Míguez MJ, Rosenberg R, Burbano X, Malow R. Cholesterol as a Mediator of Alcohol-Induced Risks for Respiratory Disease Hospitalizations among People Living With HIV. J AIDS Clin Res. 2011;Suppl 1(1):001.

30. Yang W, Bai Y, Xiong Y, Zhang J, Chen S, Zheng X, et al. Potentiating the antitumour response of CD8(+) T cells by modulating cholesterol metabolism. Nature. 2016;531(7596):651-5. https://doi.org/10.1038/nature17412.

31. Yasumasu T, Takahara K, Sadayasu T, et al. Effect of plasma lipoproteins on natural killer cell activity in the elderly population. J Gerontol A Biol Sci Med Sci. 2003;58:561-5.

\section{Publisher's Note}

Springer Nature remains neutral with regard to jurisdictional claims in published maps and institutional affiliations. 